\title{
Experimental studies of immunologically mediated enteropathy. Development of cell mediated immunity and intestinal pathology during a graft-versus-host reaction in irradiated mice
}

\author{
ALLAN MCI MOWAT, MICHELLE V FELSTEIN, ANNETTE BORLAND, \\ AND DELPHINE M V PARROTT
}

From the Department of Bacteriology and Immunology, Western Infirmary, Glasgow

\begin{abstract}
SUMmary The intestinal component of a graft-versus-host reaction (GvHR) provides a useful experimental model to elucidate the pathogenesis of clinical enteropathies which cause villus atrophy and crypt hyperplasia and which are associated with a local immune response. One to three days after induction of GvHR in heavily irradiated $(C B A x B A L B / c) F_{1}$ mice, a proliferative form of enteropathy developed. Compared with controls, these mice had increased counts of jejunal intraepithelial lymphocytes and had a four-fold increase in crypt cell production rate as well as an increase in crypt length. These changes were accompanied by a marked enhancement of splenic natural killer cell activity. After day three, the crypt cell production rate fell to zero and cytotoxic $T$ lymphocytes (CTL) which could lyse targets of host origin appeared. In parallel, mice with GvHR developed significant villus shortening and their clinical condition deteriorated. Further experiments showed that increased counts of intraepithelial lymphocytes, villus atrophy and crypt hyperplasia also occurred in grafts of fetal CBA intestine implanted under the kidney capsule of $(\mathrm{CBAxBALB} / \mathrm{c}) \mathrm{F}_{1}$ mice with GvHR. As these grafts are syngeneic to the injected CBA spleen cells, they should not be attacked by anti-host cytotoxic $T$ lymphocytes. We suggest that the proliferative and destructive components of enteropathy in GvHR are caused by lymphokines released by an antihost delayed type hypersensitivity reaction.
\end{abstract}

A graft-versus-host reaction (GvHR) in experimental animals is a useful means of inducing intestinal damage associated with a local cell mediated immune response and may therefore represent a model to study the pathogenesis of clinical enteropathies such as coeliac disease, cow's milk protein intolerance and certain parasitic infections. ' It would therefore be of interest to determine the exact nature of the cell mediated effector mechanism which damages the gut in GvHR.

Tissue damage due to a $\mathrm{T}$ lymphocyte mediated immune response involves two principal pathogenic

Address for correspondence: Dr Allan Mowat. Dept of Bacteriorology and Immunology, Western Infirmary, Glasgow G11 6NT.

Received for publication 12 February 1988 mechanisms, caused by effector cells with distinct phenotypes and functions. ${ }^{3}$ First, tissue cells may be killed directly by specific cytotoxic $\mathrm{T}$ lymphocytes. Alternatively, non-specific mediators released during a delayed type hypersensitivity response may injure an organ either directly or by recruiting other, non-specific effector cells. Our previous studies have shown that the crypt hyperplasia and increased counts of intraepithelial lymphocytes which characterise the intestinal component of a non-lethal GvHR in unirradiated mice ${ }^{+5}$ are associated with generalised recruitment of local, non-specific effector cells, including natural killer cells and mucosal mast cells, ${ }^{, 7}$ but specific antihost cytotoxic $\mathrm{T}$ lymphocytes are not detectable.' The intestinal 
damage is the result of recognition of Class II major histocompatibility complex (MHC) alloantigens on bone marrow-derived cells by $\mathrm{T}$ cells with the helper/ inducer phenotype. ${ }^{54}$ Together, these features suggest that intestinal damage in this model of GvHR is because of a local delayed type hypersensitivity response, rather than a direct cytotoxic attack on host epithelial cells.

Thus, we have proposed that a similar delayed type hypersensitivity reaction underlies the crypt hyperplasia and increased density of intraepithelial lymphocytes found in naturally occurring enteropathies associated with local cell mediated immunity. '2 Nevertheless, the most characteristic finding in these clinical enteropathies is villus atrophy and we have been unable so far to reproduce this feature using a GvHR in mature, unirradiated mice. ${ }^{5 \times 9}$ Therefore, it remains possible that villus atrophy is caused by a different mechanism from that which causes crypt hyperplasia. Earlier studies did indicate that small intestinal villus atrophy occurred during a lethal GvHR in irradiated hosts, ${ }^{1012}{ }^{12}$ but the pathogenesis of intestinal damage in this model was not investigated in detail. The present studies were designed firstly to examine whether the intestinal component of GvHR in irradiated mice would reproduce the more severe features of clinical enteropathies and, secondly, to study the immunological basis of this form of GvHR. We have therefore assessed in parallel the evolution of intestinal damage and development of specific and non-specific cytotoxicity in irradiated $(\mathrm{CBAxBALB} / \mathrm{c}) \mathrm{F}_{1}$ mice with GvHR.

\section{Methods}

MICE

$\mathrm{CBA}\left(\mathrm{H}-2^{k}\right)$, and $(\mathrm{CBAx} \mathrm{BALB} / \mathrm{c}) \mathrm{F}_{1}\left(\mathrm{H}-2^{\mathrm{kxd}}\right)$ mice of both sexes were obtained from departmental stocks. All mice were first used at 12-16 weeks of age.

PREPARATION OF LYMPHOCYTES

Spleens and thymuses were removed immediately after donor mice had been killed and single cell suspensions prepared by mincing tissues through a fine wire mesh filter into RPMI 1640 (Gibco Biocult) supplemented with $5 \%$ newborn calf serum (Gibco Biocult). After washing three times in medium, cells were counted and viability assessed by phase contrast microscopy.

INDUCTION OF GVHR

Host mice received 950 rads irradiation from a $300 \mathrm{KeV} x$-ray source (Dynaray) at a distance of 100 $\mathrm{cm}$ and a dose rate of $250 \mathrm{rad} / \mathrm{min}$. Twenty four hours later, mice were reconstituted with $4 \times 10^{7}$ viable spleen cells iv and were then maintained on drinking water containing $100 \mathrm{mg} / \mathrm{l}$ neomycin sulphate (Sigma). As controls for the radiosensitivity and regeneration of host type natural killer cells, host mice were left unreconstituted after irradiation, while irradiated mice of donor origin were reconstituted with syngeneic spleen cells to assess the regeneration of donor natural killer cells in a syngeneic environment. Control mice in studies of intestinal GvHR were $F_{1}$ mice reconstituted with syngeneic cells, to assess mucosal regeneration under normal conditions.

IMPLANTATION OF ANTIGEN FREE GRAFTS OF INTESTINE

Pieces of foetal small intestine were implanted under the kidney capsule of adult (CBAxBALB/c) $F_{1}$ mice as described previously. ${ }^{5}$ Briefly, animals were anaesthetised with Sagatal (M \& B Ltd) and a 1-2 $\mathrm{mm}$ piece of small intestine from $18-19$ day old fetuses of either CBA or $(\mathrm{CBA} \times \mathrm{BALB} / \mathrm{c}) \mathrm{F}_{\text {, }}$ origin was placed under the capsule of each kidney, using a $21 \mathrm{G}$ plastic cannula (Argyle Medicut). The grafts were allowed to vascularise for five to six weeks before host animals were irradiated and a GVHR induced as described above.

MEASUREMENT OF SPECIFIC AND NON-SPECIFIC CYTOTOXICITY

Natural killer activity was assayed using YAC-1 target cells, while P815 mastocytoma cells were used to measure $\mathrm{H}-2^{\mathrm{d}}$-specific cytotoxic $\mathrm{T}$ lymphocyte activity, using a standard microcytotoxicity assay described in detail elsewhere. ${ }^{7}$ Briefly, $2.5 \times 10^{\prime}$ tumour target cells were labelled with $50 \mu \mathrm{Ci}$ sodium ${ }^{5}$ chromate (Amersham) in $0.5 \mathrm{ml}$ for 45 minutes at $37^{\circ} \mathrm{C}$, washed six times in RPMI $/ 5 \%$ NCS and 10()$\mu \mathrm{l}$ aliquots containing $2 \times 10^{4}$ cells added to the wells of a V-bottomed microtitre plate (Titertek). One hundred microlitre aliquots of spleen cells from GvHR or control mice were then added to give effector:target $(\mathrm{E}: \mathrm{T})$ ratios of $50: 1$ and $25: 1$. After four hours culture at $37^{\circ} \mathrm{C}$ in $5 \% \mathrm{CO}_{2}$ in air, $100 \mu \mathrm{l}$ supernatant was removed from each well and ${ }^{51} \mathrm{Cr}$ specific radioactivity measured in a $\gamma$-counter. The $\%$ cytotoxicity was calculated as follows:

$$
\% \text { Cytotoxicity }=\frac{(\text { Experimental release }- \text { spontaneous release })}{(\text { Maximum release }- \text { spontaneous release })} \times 10(\%)
$$

In all experiments, $10 \%$ Triton $\mathrm{X}$ (Sigma) was used to obtain maximum release. In natural killer assays, spontaneous release was obtained using normal thymocytes as a source of natural killer-inactive filler cells, while normal CBA spleen cells were used for spontaneous release in cytotoxic $T$ lymphocyte 
assays. The results shown are means of quadruplicate assays and variability between wells was normally $<10 \%$.

ASSESSMENT OF INTESTINAL GVHR

The intestinal phase of GvHR was assessed as described previously. ${ }^{+5}$ Intraepithelial lymphocyte counts were performed on $\mathrm{H}$ and $\mathrm{E}$ stained sections of jejunum, taken $10 \mathrm{~cm}$ from the pylorus and expressed as IEL/100 epithelial cells. Villus and crypt lengths and crypt cell production rates (CCPR) were measured in adjacent specimens of jejunum which was prepared and stained in bulk by the modified Feulgen reaction, as first described by Clarke $1970 . .^{\text {th }}$ Briefly, mice were killed at intervals of 20-90 minutes after receiving $7.5 \mathrm{mg} / \mathrm{kg}$ colchicine (Sigma) to cause metaphase arrest and $1 \mathrm{~cm}^{2}$ pieces of jejunum removed and fixed in $75 \%$ ethanol $/ 25 \%$ acetic acid for six to 24 hours. After staining with

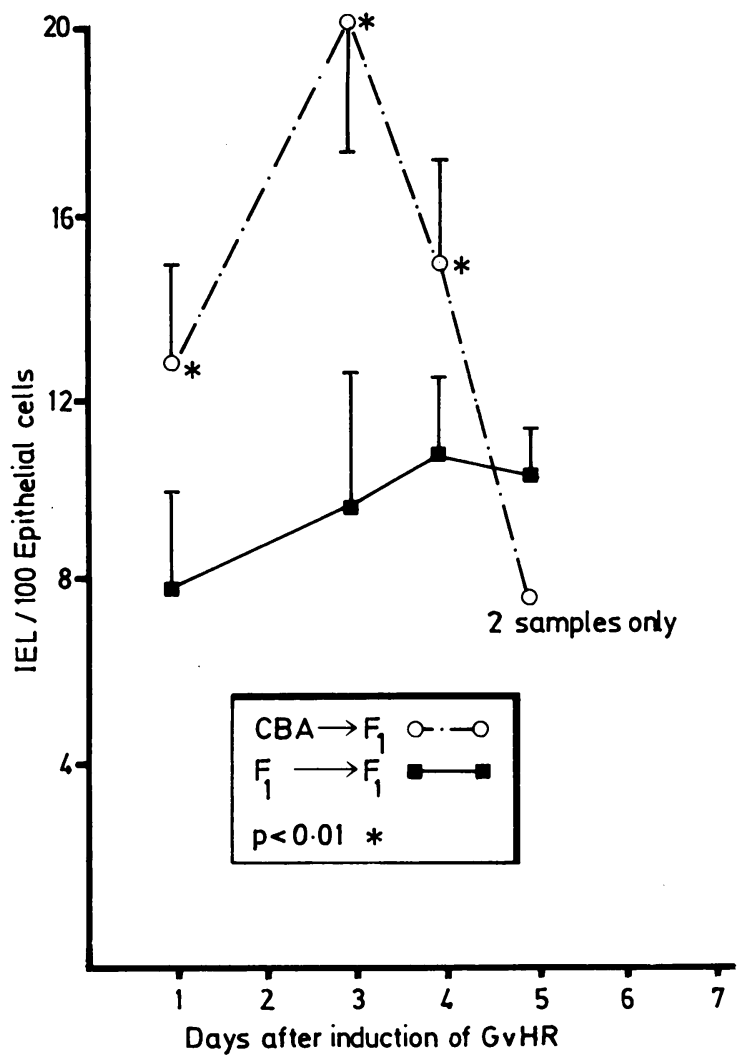

Fig. 1 Intestinal phase of $G v H R$ in irradiated $(C B A \times B A L B / c) F_{1}$ mice. Intraepithelial lymphocyte counts in the jejunum of $F_{1}$ mice at intervals after transfer of $4 \times 10^{7}$ CBA of $F_{1}$ spleen cells. Results shown are mean IEL/100 epithelial cells (ISD) for four to five mice/group, unless otherwise stated.

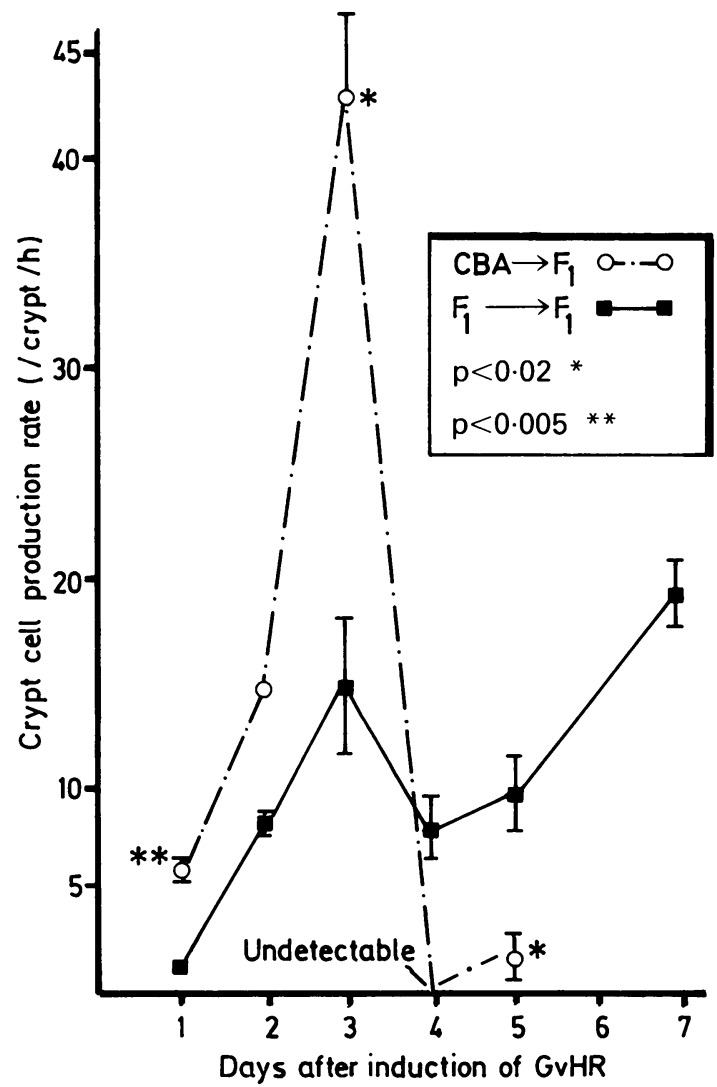

Fig. 2 Intestinal phase of $G v H R$ in irradiated (CBAxBALB/c) $F_{1}$ mice. Crypt cell production rates in the jejunum of $F_{1}$ mice with $G v H R$ and in syngeneically reconstituted $F_{1}$ mice. Results shown are means (ISD) for three to four mice/group.

Schiff reagent (Difco), slices of mucosa were cut with a cataract knife (Weiss Ltd) using a dissecting microscope. Villus and crypt lengths were measured using an eyepiece micrometer under conventional microscopy and the number of metaphases per crypt counted. The CCPR was then obtained by linear regression analysis of metaphase accumulation against time. In each specimen, 10 villi and crypts were counted.

STATISTICAL ANALYSIS

Groups of means and standard deviations were compared by Student's $t$ test, while crypt cell production rates were compared using covariance analysis.

\section{Results}

PROGRESS OF GVHR IN IRRADIATED

( CBAXBALB/C)F $F_{1}$ MICE

$(\mathrm{CBA} \times \mathrm{BALB} / \mathrm{c}) \mathrm{F}_{1}$ mice given $4 \times 10^{7} \mathrm{CBA}$ spleen 
cells after lethal irradiation had no overt clinical abnormalities for the first three to four days after cell transfer. By days four to five, mice with GvHR developed an acute runting disease typified by abnormal gait, ruffled fur, diarrhoea and weight loss, and all animals died on days six to seven. Irradiated CBA or $F_{1}$ mice given $4 \times 10^{7}$ syngeneic spleen cells as controls, survived indefinitely, while most unreconstituted $F_{1}$ mice died within 20 days of irradiation.

INTESTINAL PHASE OF GVHR

The jejunum of syngeneically reconstituted $F_{1}$ mice showed few histological abnormalities after irradiation, other than the expected depletion of lymphoid cells in the lamina propria, epithelium and Peyer's patches. Mice with GvHR had evidence of lymphocytic infiltration of the mucosa by days one to two after ceil transfer and, after day five, diffuse mucosal necrosis and complete villus atrophy precluded morphometric analysis.

INTRAEPITHELIAL LYMPHOCYTE COUNTS

$(\mathrm{CBAxBALB} / \mathrm{c}) \mathrm{F}_{1}$ mice reconstituted with syngeneic spleen cells showed a gradual rise in IEL count throughout the course of the experiment, reaching $10 \cdot 1(1.4)$ by day five, reflecting the recovery of the mucosal lymphocyte population from irradiation
(Fig. 1). F1 mice with GvHR had a significantly increased IEL count compared with these controls by day one $(12.8(2.2) \cup 7.9(2 .()) p<(0.01)$ and this rose to a maximum of $21 \cdot 2(2 \cdot 8)$ on day three. Thereafter, the IEL counts in mice with GvHR fell and, at later times, became difficult to estimate because of the evolving mucosal damage.

\section{CRYPT CELL PRODUCTION RATE ANI) CRYPT LENGTH}

The cytostatic effect of the irradiation was evidenced by the very low CCPR seen in syngeneically reconstituted $F_{1}$ mice, one day after irradiation (Fig. $2 \quad 1 \cdot 2$ $(0 \cdot 2))$. Thereafter, the CCPR recovered rapidly and this was paralleled by a progressive increase in crypt length (Fig. 3a). Similar results were found on examination of the intestine of irradiated $F_{1}$ mice not reconstituted with spleen cells (data not shown).

Mice with GvHR had a significantly increased CCPR on day one (Fig. 2 5.8 (().5) $\mathrm{p}<() \cdot()(0) 5)$ and this rose to an extremely high level of $42.9(4 \cdot())$ on day

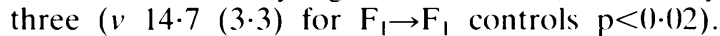
Thereafter, the deteriorating morphology made estimation of CCPR difficult in many samples. Nevertheless it could be shown that epithelial cell turnover ceased abruptly on day four, when no normal metaphases were detectable at any time after

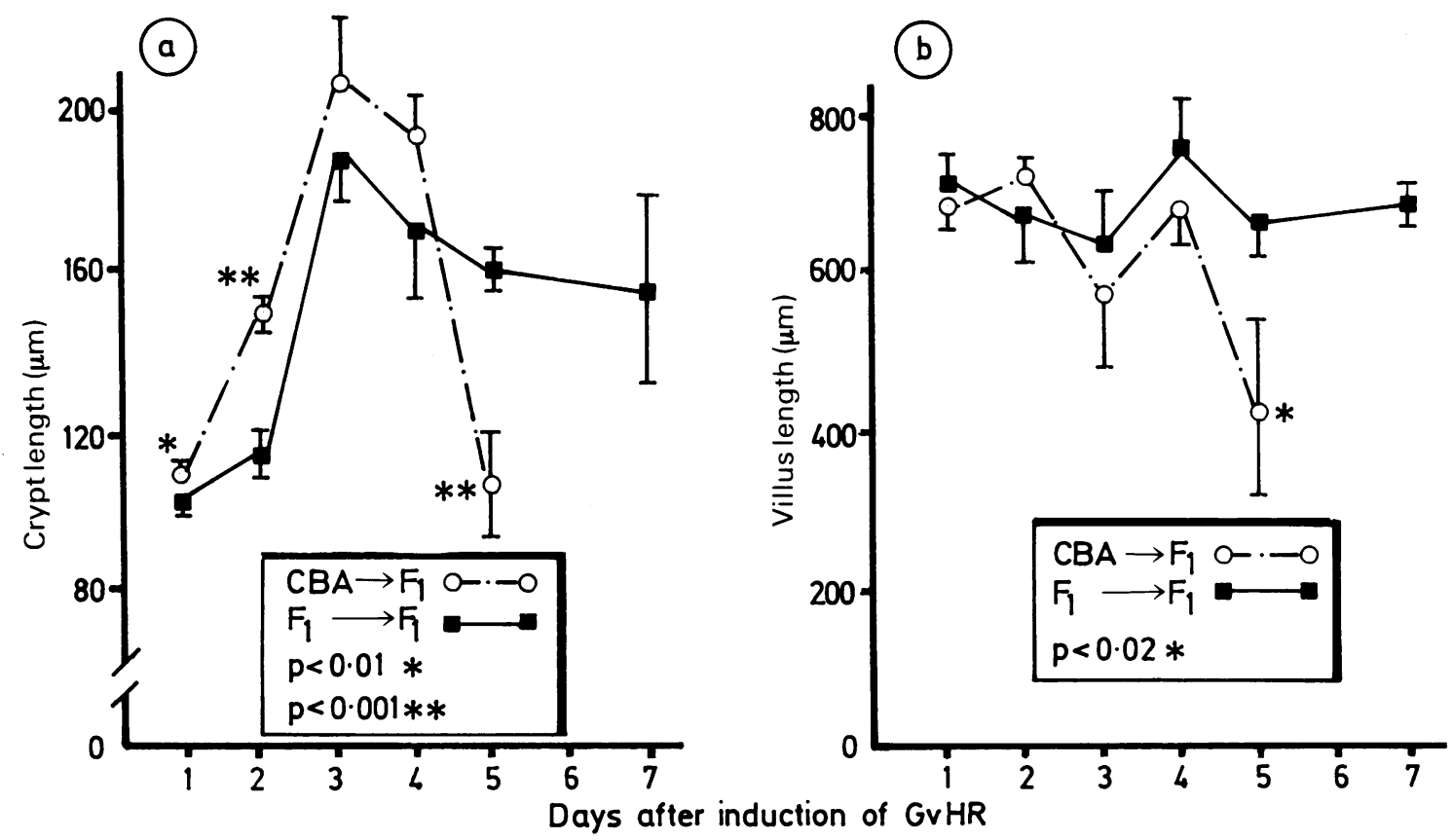

Fig. 3 Intestinal phase of $G v H R$ in irradiated $(C B A x B A L B / c) F_{1}$ mice. Crypt $(a)$ and villus $(b)$ lengths in the jejunum of $F_{1}$ mice with $G v H R$ and in syngeneically reconstituted $F_{1}$ mice. Results shown are mean lengths (I SD) for three to four mice/group. 
colchicine. This feature could also be observed using conventional histology. The GvHR specimens suitable for analysis on day five also showed a very low CCPR which was significantly less than in control mice. In parallel with these changes in CCPR, mice with GvHR had significant crypt lengthening on days one and two, reaching a maximum of $207 \cdot 8(16 \cdot 0)$ $\mu \mathrm{m}$ on day three (Fig. 3a $v$ 188.3(11.5) $\mu \mathrm{m}$ for $\mathrm{F}_{1} \rightarrow \mathrm{F}_{1}$ controls) but had significantly lower crypt lengths then controls by day four $(108.2(10.8) v 161 \cdot 6(4.5)$ $\mu \mathrm{m} \mathrm{p}<0 \cdot 001)$.

\section{VILLUS LENGTH}

Villus lengths remained virtually constant, in syngeneically reconstituted (Fig. 3b) and in unreconstituted $F_{1}$ mice (data not shown). Villus lengths in mice with GvHR were similar to those in $F_{1} \rightarrow F_{1}$ mice until day five, when significant villus atrophy was observed. Interestingly, this occurred after the sudden cessation of CCPR and no significant villus alterations were found before the initial increase in CCPR. Thus, the intestinal damage during the GvHR in irradiated mice is characterised by an early, proliferative stage of crypt hyperplasia and increased numbers of intraepithelial lymphocytes which precedes the fully developed picture of villus atrophy and mucosal destruction.

\section{SPECIFIC AND NON-SPECIFIC CYTOTOXICITY IN}

( CBAXBALB/C) F 1 MICE WITH GVHR

The evolution of the antihost immune response in GvHR was followed by assessing specific antihost cytotoxic $T$ lymphocyte activity and by measuring the level of splenic natural killer cell activity, which we have shown previously to reflect the non-specific effects of antihost delayed type hypersensitivity. ${ }^{715}$

The splenic natural killer activity of $F_{1}$ mice was virtually eliminated by the dose of irradiation used and remained very low throughout the seven days of study (Fig. 4b). Spleen natural killer activity was also absent in CBA hosts reconstituted with syngeneic CBA spleen cells until two to three days after cell transfer, when a progressive recovery began. In contrast, in GvHR mice, significant natural killer levels were already apparent on day one and rose to a peak on days two to three, when syngeneically reconstituted mice still had little or no natural killer activity. Thereafter, natural killer activity in GvHR

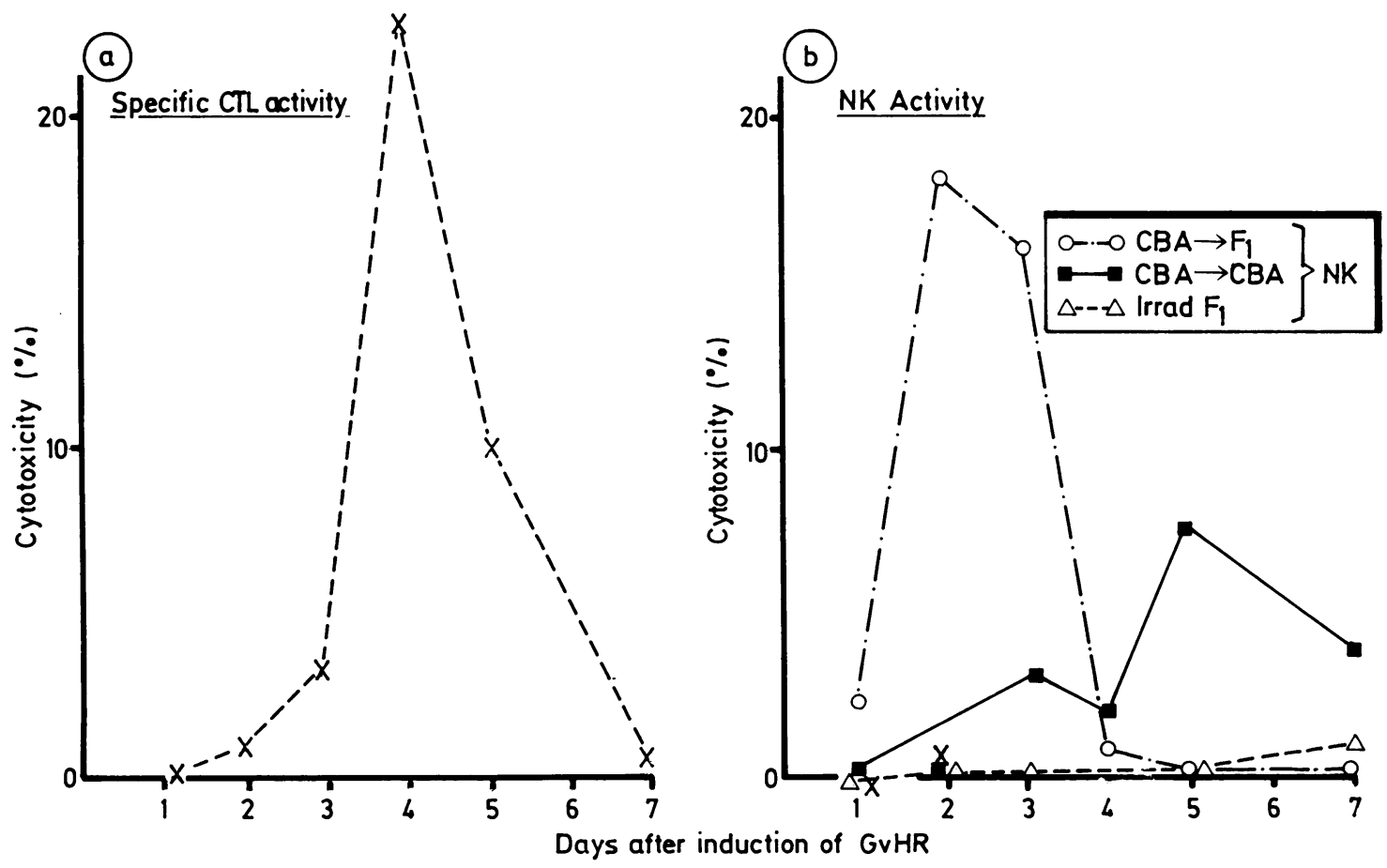

Fig. 4 Specific antihost cytotoxic Tlymphocyte (a) and natural killer cell activity (b) during a GvHR in irradiated $(C B A x B A L B / c) F_{1}$ mice. Spleen cells were pooled from five to six mice with $G v H R$ and tested for cytotoxic Tlymphocyte activity against $P 815\left(H-2^{`}\right)$ target cells and for natural killer activity against $Y A C-1$ target cells, using Effector:Target cell ratios of 50:1. In natural killer assays, control spleen cells were from 5-6 irradiated, unreconstituted $F_{1}$ mice or from syngeneically reconstituted $C B A$ mice. 


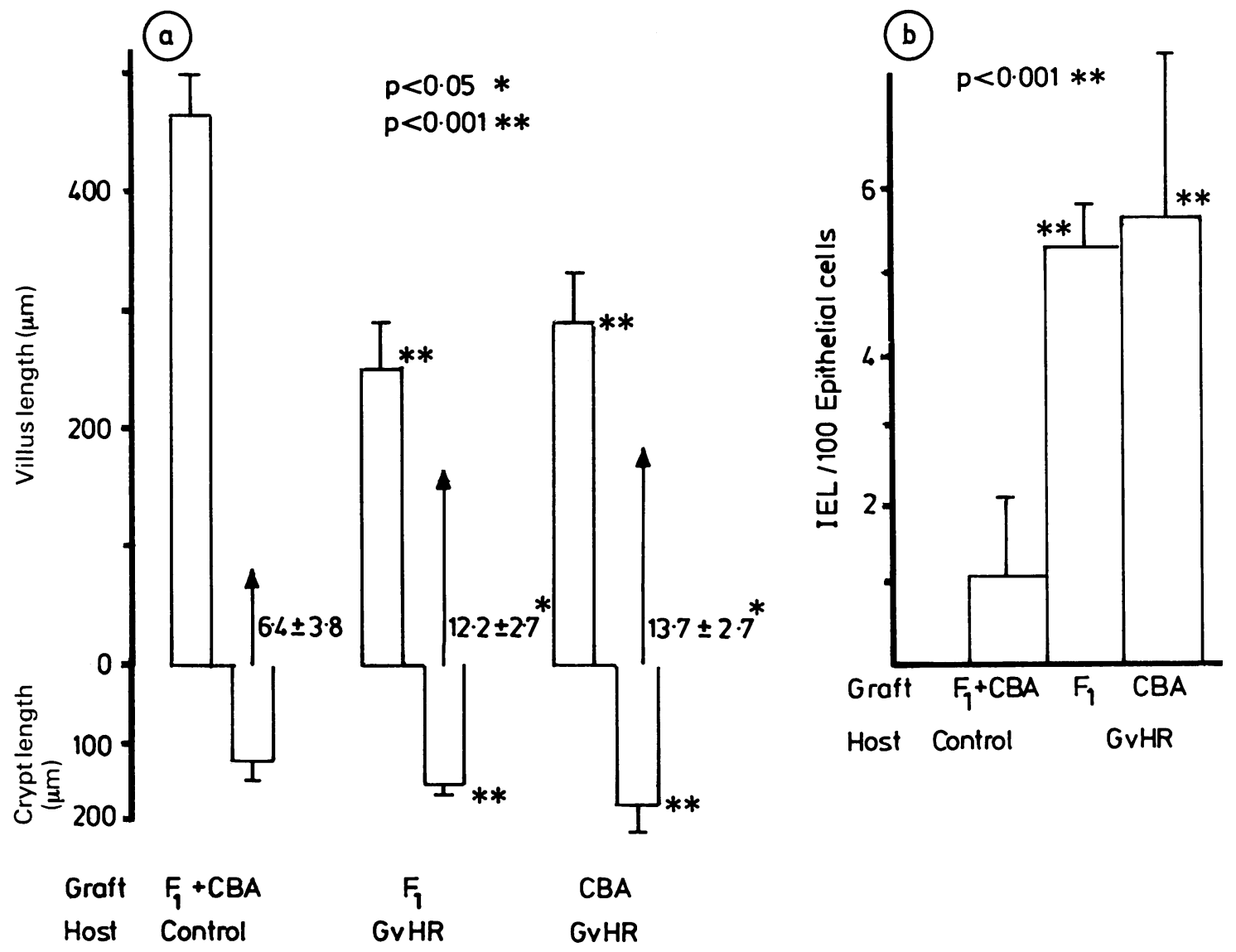

Fig. 5 Intestinal pathology in irradiated $(C B A x B A L B / c) F_{1}$ mice with $G v H R$ occurs as a bystander phenomenon. Mucosal architecture (a) and intraepithelial lymphocyte counts $(b)$ in grafts of $F_{1}$ or $C B A$ fetal small intestine implanted in $(C B A x B A L B / c) F_{1}$ mice before irradiation and transfer of $4 \times 10^{7} C B A(G v H R)$ or $F_{1}$ (control) spleen cells. (a) Results shown are mean villus and crypt lengths (ISD), while arrows represent crypt cell production rates. (b) Results shown are mean IEL/100 epithelial cells (1SD) for four to five grafts/group of GvHR mice and eight grafts in control group.

mice fell rapidly to zero after day four. The lysis of YAC-1 $\left(\mathrm{H}-2^{\mathrm{k} / \mathrm{d}}\right)$ cells did not merely reflect specific recognition of host-type $\mathrm{H}-2^{\mathrm{d}}$ alloantigens as there was clearly a reciprocal relationship between the ability of GvHR cells to lyse YAC-1 and specific $\mathrm{H}-2^{\mathrm{d}+}$ P815 targets (see below).

Specific cytotoxic T lymphocyte activity did not appear in mice with GvHR until day three and peaked on day four, when natural killer activity was already markedly depressed (Fig. 4a). Cytotoxic T lymphocyte activity then declined as the clinical condition of the mice deteriorated.

Thus, enhanced natural killer activity occurs very soon after inducing a GvHR in irradiated mice and a marked decrease in natural killer levels coincides with the parallel development of specific cytotoxic $T$ lymphocyte activity and the onset of overt disease.
INTESTINAL PATHOLOGY OCCURS AS A

BYSTANDER PHENOMENON OF GVHR

The close association between the appearance of cytotoxic $T$ lymphocytes and villus atrophy suggested that the mucosal destruction was due to a cytotoxic attack on host enterocytes. To test this hypothesis, we examined whether the intestinal damage only occurred when the intestinal tissues presented an allogeneic target to the donor $T$ cells.

$(\mathrm{CBAxBALB} / \mathrm{c}) \mathrm{F}_{1}$ mice were given grafts of either $\mathrm{CBA}$ or $(\mathrm{CBAxBALB} / \mathrm{c}) \mathrm{F}_{1}$ fetal small intestine five to six weeks before irradiation and induction of a GvHR with $4 \times 10^{7}$ CBA spleen cells. Five days after cell transfer, $C B A$ and $F_{1}$ grafts implanted in syngeneically reconstituted $F_{1}$ hosts showed evidence of mucosal regeneration with active crypts and intact villi of normal appearance. The values for CCPR, 
crypt length and villus length were identical in these two groups of control grafts and for simplicity these results are combined (Fig. 5a). On day five of the GvHR, grafts of $F_{1}$ intestine had significant villus atrophy compared with control grafts implanted in syngeneically reconstituted hosts $(258(25.4) \mu \mathrm{m} v$ $468 \cdot 2(35 \cdot 8) \mu \mathrm{m} \mathrm{p}<0 \cdot 001)$. At this time, the grafts in GvHR mice also still had significant crypt lengthening and a marked increase in CCPR compared with control grafts. The important finding from this experiment was that grafts of CBA gut developed identical intestinal changes when implanted in $F_{1}$ mice with GvHR, with significant villus atrophy (293.4 (40.9) $\mu \mathrm{m} \mathrm{p}<0.001)$, crypt lengthening (188.5 $(31.7) \mu \mathrm{m} v 130.5(15.5) \mu \mathrm{m} \mathrm{p}<0.001)$ and increased CCPR compared with control grafts. Furthermore, both $F_{1}$ and CBA grafts in mice with GvHR showed significant increases in intraepithelial lymphocyte counts compared with controls (Fig. 5b 5.4 (0.5) and $5 \cdot 7(2 \cdot 2)$ respectively $v 1 \cdot 1(1 \cdot 1))$. Thus, the intestinal pathology occurs even when the gut itself is syngeneic to the donor cells used to induce the GvHR and should not be due to direct attack by specific cytotoxic T lymphocytes.

\section{Discussion}

The results presented here show that a GvHR in irradiated mice produces a biphasic enteropathy, each stage of which is accompanied by distinct forms of antihost cell mediated immunity. An initial proliferative stage of intestinal GvHR is associated with a marked enhancement of non-specific cytotoxicity, while the onset of the destructive phase is accompanied by the appearance of specific antihost cytotoxic $T$ lymphocyte activity. Nevertheless, all the intestinal features occur in tissue which is syngeneic to the donor cells used to induce the GvHR, indicating that specific cytotoxic $\mathrm{T}$ lymphocytes are not essential for the development of either crypt hyperplasia or villus atrophy.

The mucosal alterations found in the first two to three days of GvHR in irradiated mice were characterised by early increases in CCPR and in intraepithelial lymphocyte count and thus are identical to those found throughout the entirely proliferative GvHR in unirradiated mice. ${ }^{56}$ It should be noted that as the crypt hyperplasia preceded the development of villus atrophy in the present study and occurs when villus atrophy is absent in unirradiated hosts, it must be a primary consequence of the GvHR. In both instances, the crypt hyperplasia is paralleled by enhanced natural killer cell activity and occurs in the absence of significant specific cytotoxic T lymphocyte activity.' As described above, the intestinal pathology during a GvHR in unirradiated mice is due to recognition of class II major histocompatibility complex alloantigens on circulating bone marrow derived cells by donor $T$ cells of the helper/inducer phenotype ${ }^{x y}$ while the natural killer cell activation is preceded by an antihost delayed type hypersensitivity response. ${ }^{15}$ These findings are strong circumstantial evidence that a local delayed type hypersensitivity response, rather than classical cytotoxic $\mathrm{T}$ lymphocyte activity, is the effector $\mathrm{T}$ cell response responsible for the mucosal changes found in unirradiated mice with GvHR. Others have also shown that the induction of crypt hyperplasia and lymphocytic infiltration in irradiated mice with GvHR is class II MHC-restricted ${ }^{16}$ and is associated with production of lymphokines by mucosal lymphocytes. ${ }^{17}$ Therefore, although we did not study antihost delayed type hypersensitivity directly in the present investigation, we would propose that a delayed type hypersensitivity response is also responsible for the early, proliferative phase of GvHR in irradiated mice.

The principal focus of the current investigation was to study the pathogenesis of a destructive enteropathy which included villus atrophy. Our results showed that villus atrophy was a feature of established GvHR which paralleled the clinical deterioration of the mice and which was associated with the appearance of specific antihost cytotoxic T lymphocytes. Although the simplest explanation for the development of villus atrophy would be that antihost cytotoxic $\mathrm{T}$ lymphocytes exert a direct cytotoxic effect against host enterocytes, this explanation is not compatible with our finding that an identical pattern of mucosal pathology occurred in grafts of fetal CBA intestine which were syngeneic to the donor cells used to induce the GvHR. As the epithelium of these grafts does not present an allogeneic target to specific effector cells, antihost cytotoxic $\mathrm{T}$ lymphocytes cannot cause the destructive enteropathy found in this experiment. A 'bystander phenomenon' has been described previously in intestinal grafts during a proliferative GvHR in unirradiated mice and is normally ascribed to the action of lymphocytederived soluble mediators. ${ }^{56}$ Although necrotic and proliferative changes have been noted in syngeneic gut grafts implanted in irradiated mice with GvHR, these alterations have not been quantified previously ${ }^{1718}$ and our study is the first to detail the development of villus atrophy as a bystander phenomenon in GvHR. Thus, soluble mediators may not only be responsible for the crypt hyperplasia and recruitment of lymphocytes, found during a proliferative enteropathy, but may also cause the more severe form of enteropathy characterised by villus atrophy. We suggest that the transition from mucosal proliferation to destruction may reflect continued or 
unusually high production of lymphokines released by the rapidly progressive antihost immune response which occurs in irradiated hosts. In addition, we consider the cytotoxic $\mathrm{T}$ lymphocytes appear as an epiphenomenon of this sustained antihost immune response, because of high levels of mediators such as interleukin 2 or $\gamma$-interferon (IFN).

One additional feature of the transition from a proliferative to a destructive enteropathy was that the appearance of villus atrophy was preceded by the sudden cessation of crypt cell mitotic activity. This phenomenon has been found in subsequent experiments on this model of GvHR and is clearly an important component of intestinal GvHR in irradiated hosts. As lymphokines such as IFN or lymphotoxin, are cytostatic to a wide range of tissue cells ${ }^{1920}$ inhibition of epithelial cell turnover may be the lymphokine mediated event which contributes to mucosal destruction. We are currently studying this possibility in more detail and it would also be of interest to examine whether a similar inhibition of cell proliferation occurs in other tissues of irradiated mice at the same stage of a GvHR.

In conclusion, our results indicate that the destructive intestinal pathology caused by a GvHR in irradiated mice reflects the extreme consequences of the same mucosal cell mediated immune response which causes a proliferative enteropathy in unirradiated mice with GvHR. Together with previous work, our study suggests that this intestinal cell mediated immune response has many features of a local delayed type hypersensitivity reaction and that lymphokines play the major pathogenic role. The pattern of mucosal pathology in GvHR is similar to that found in clinical enteropathies, including coeliac disease and CMPI, supporting the hypothesis that these disorders reflect a biphasic response of the mucosa to lymphokines released during a delayed type hypersensitivity response to local antigen. ${ }^{21}$

This study was supported by MRC Grants G8224559CA and G8605634CA. Dr A Mowat is in receipt of an MRC Senior Clinical Fellowship and Dr Annette Borland was supported by a Vacational Scholarship from the Wellcome Trust.

\section{References}

1 Ferguson A, Mowat AMcI. Immunological mechanisms in the small intestine. In: Wright $\mathrm{R}$, ed. Recent advances in gastrointestinal pathology. Eastbourne: WB Saunders, 1980: 93-103.

2 Mowat AMcI. The immunopathogenesis of food sensitive enteropathies. In: Newby TJ, Stokes CR, eds. Local immune responses of the gut. Florida: CRC Press, 1984: 199-225.

3 Sprent J, Webb SR. Function and specificity of T cell subsets in the mouse. Adv Immunol 1988 (In press).

4 MacDonald TT, Ferguson A. Hypersensitivity reactions in the small intestine III. The effects of allograft rejection and of GvHD on epithelial cell kinetics. Cell Tiss Kinet 1977; 10: 301-12.

5 Mowat AMcI, Ferguson A. Hypersensitivity reactions in the small intestine 6. Pathogenesis of the graft-versushost reaction in the small intestinal mucosa of the mouse. Transplantation 1981; 32: 238-43.

6 Mowat AMcI. Ferguson A. Intraepithelial lymphocyte count and crypt hyperplasia measure the mucosal component of the graft-versus-host reaction in mouse small intestine. Gastroenterology 1982; 83: 417-23.

7 Borland A, Mowat AMcI, Parrott DMV. Augmentation of intestinal and peripheral natural killer cell activity during the graft-versus-host reaction in mice. Transplantation 1983; 36: 513-9.

8 Mowat AMCI, Borland A, Parrott DMV. Hypersensitivity reactions in the small intestine 7 . The intestinal phase of murine graft-versus-host-reaction is induced by Lyt $2^{-} \mathrm{T}$ cells activated by $\mathrm{I}-\mathrm{A}$ alloantigens. Transplantation 1986; 41: 192-8.

9 Mowat AMcI. Ia ${ }^{+}$bone marrow derived cells are the stimulus for the intestinal phase of murine graft-versushost reaction. Transplantation 1986; 42: 141-4.

10 Reilly RW, Kirsner JB. Runt intestinal disease. Lab Invest 1965; 14: 102-7.

11 Cornelius EA. Protein-losing enteropathy in the graftversus-host reaction. Transplantation 1970; 9: 247-52.

12 Woodruff JM, Hansen JA, Good RA, Santos GW, Slavin RE. The pathology of the GvHR in adults receiving BM transplants. Transplant Proc 1976; 8: 675-84.

13 Ferguson A, Parrott DMV. Growth and development of antigen-free grafts of foetal mouse intestine. $J$ Pathol 1972; 106: 95-101.

14 Clarke RM. Mucosal architecture and epithelial cell production rate in the small intestine of the albino rat. J Anat 1970; 107: 519-29.

15 Mowat AMcI, Borland A, Parrott DMV. Augmentation of natural killer cell activity by anti-host delayedtype hypersensitivity during the graft-versus-host reaction in mice. Scand J Immunol 1985; 22: 389-99.

16 Piguet P-F. GvHR elicited by products of Class I or Class II loci of the MHC: analysis of the response of mouse T lymphocytes to products of Class I and Class II loci of the MHC in correlation with GvHR-induced mortality, medullary aplasia and enteropathy. $J$ Immunol 1985; 135: 1637-43.

17 Guy-Grand D, Vassalli P. Gut injury in mouse graftversus-host reaction. Study of its occurrence and mechanisms. J Clin Invest 1986; 77: 1584-95.

18 van Bekkum DW, Knaan S. Role of bacterial microflora in development of intestinal lesions of GvHR. J Natl Canc Inst 1977; 58: 787-90.

19 Lee SH, Aggarwal BB, Rinderknecht E, Assisi F, Chiu H. The syngergistic anti-proliferative effect of $\gamma$ interferon and human lymphotoxin. J Immunol 1984; 133: $1083-6$.

20 Trinchieri G, Perussia B. Immune interferon: a pleiotropic lymphokine with multiple effects. Immunol Today 1986; 6: 131-6.

21 Ferguson A, MacDonald TT. Effects of local delayed type hypersensitivity on the small intestine. Ciba Foundation Symposium 1977; 46: 305-27. 